\title{
Research on Differentiation of Accidents at Work Considering Demographic Features of Workers in Steel Sector in Poland
}

\author{
Tomasz Malysa, Bozena Gajdzik
}

\author{
Silesian University of Technology \\ Krasinskiego st. 8, 40-019 Katowice, Poland \\ E-mail.tomasz.malysa@polsl.pl; bozena.gajdzik@polsl.pl
}

cross $^{\text {ref }}$ http://dx.doi.org/10.5755/j01.ee.32.2.22506

\begin{abstract}
This article focuses on the number of accidents at work in enterprises in the steel industry. Accidents have a significant effect on the operations of enterprises due to the social and economic costs they generate. This article presents the dependence between the number of accidents at work, demographic characteristics (sex, age) and work experience of injured persons, which allows for the identification of risk groups based on to the tested feature. The scope of the analysis covers the structure of accidents at work in the steel industry in the years 2009-2015. The aim of this article is to present the dependence between the number of accidents at work and the demographic characteristics and work experience of workers employed in the industry under examination. The conducted analysis led to the conclusion that there is a relation between the number of accidents at work and the demographic characteristics of persons sustaining an accident at work. In the period between 2009-2015, male workers aged 30-39 were involved in accidents at work the most frequently. The research methodology applied in this article consists of: absolute and generic analysis of work accidents, ratio analysis and statistical analysis of the relation between the number of accidents at work and the demographic characteristics of workers injured in accidents. The applied methodology of analysis of accidents at work may be used for a benchmark analysis of various industry sectors in any country or the same sectors in various countries.
\end{abstract}

Keywords: Accidents at Work; Legal Requirements; Statistical Analysis; Metallurgical Enterprises; Safety at Work.

\section{Introduction}

The process of getting the answers on such questions may be a part of metallurgical work accidents comparative analysis in the whole world. Work accidents result in economic and social costs and their occurrence affects the operations of production companies. This may result in production downtimes, delivery and customer order realization delays (Brown et al., 2000). The safety of work is specified by the applicable general and specific legal rules in individual countries internationally. The employers all over the world are obliged to ensure and provide safe, hygienic and ergonomic conditions of work (Council Directive 89/391/EEC; Malysa et al., 2016; Malysa et al., 2017). The issue of work safety is particularly important in production companies, especially those in the branches with high levels of danger. In Poland, it is metallurgy sector (Gajdzik et al., 2015).

In order to protect the operations of companies, it is important to develop and implement the methods and techniques of work accidents prevention in individual industry branches. The approach to the safety management should take the technological profile of the company into account. According to the contemporary concepts of safety management it is effective to apply technical, organisational and psychological measures. The technical solutions most frequently reduce the accident risk at root (the application of barriers preventing the worker from getting into the danger zone) while the organisational measures are meant to influence the development of work procedures. The psychological measures concentrate on the engagement of workers and their significant influence on work safety culture development at work.
The development of work safety culture is often a subject of study (Nowacki, 2019; Guldenmund, 2000; Cox \& Cheyne, 2010; Yangho et al., 2016, Sorensen, 2002, Nielsen, 2014, Cox \& Flin, 1998; Cox \& Cox, 1996) because it is the chance to engage all the workers in work safety activities that may become a successful solution for work safety issues (Glendon \& Stanton, 2000). One of the results of these studies are models describing security systems on the example of the industry sector. The models are both descriptive (for example historical models) (Markey \& Patmore, 2011; Wallace, 1987) and statistical (Kim \& Cho, 2016; Long \& Freese, 2014).

One of the solutions that has influence on safety improvement is the application of work safety management system along with the measures reducing the risk of an accident (Santos et al., 2013). The implementation of the management system (Granerud and Rocha, 2011) provides the employers with the tools allowing to take up the challenges and limiting the behaviours that may lead to the accidents at work. The systems used in Poland are based on 18000 series standards. They deal with the following aspects: the requirements and guidelines for professional risk assessment and the stages of system implementation. In other countries (Carrillo et al., 2012), as well as in Poland, the standard OHSAS is used which is compatible with the 18000 series standards. Currently, the new international standard ISO 45001 is being formulated which will replace the BS OHSAS 18001 and polish standards of PN-N 18000 series (PN-N 18001:2004, PN-N 18002:2011, PN-N 18004:2001). The above mentioned standard is expected to have a similar structure to the standards ISO 9001 and ISO 14001, thus it will allow to 
unify the structure of the workers safety management system. The applied change will probably result in the easier implementation and certification of several ISO standards simultaneously. Such solution would make the management systems in the companies more efficient and would increase the synergy of results. The aim of management systems is to control the dangers that may adversely affect the health and safety of workers. The implementation of the system allows to keep the professional risk at an acceptable level (Koursi et al., 2007) not only as a result of complying with legal requirements, but as an element of management systems effectiveness assessment. The implementation of the solutions focused on work safety improvement is one of the basic areas of operation for contemporary companies LM tools can also be included (Furman et. al., 2018). The improvement of the financial profitability is intertwined with the integrated policy focused on quality assurance, protection of the environment and the assurance of safe workplace conditions. The synergy of economic and social measures reduces the faultiness of the products, timewasting and ensures the customer satisfaction.

In individual industry branches, accident level is differentiated and dependent on professional structure (work experience) and demographic structure (sex, age) accident level. Research is conducted on the level of influence of the characteristics of the injured (e.g. age, seniority) on accidents at work (Hola \& Szostak, 2017). The individual professional groups are exposed to the harmful rates, and the demographic conditions contribute to the increase of the number of accidents and occupational diseases. This article focuses on the impact of demographic rates on the number and structure of workplace accidents by the example of metallurgical industry in Poland. The article is supplementing the knowledge on the human rate influence on the accident rate in the researched industry.

The general purpose of this article was to present the research methodology for work accidents in metallurgical industry in Poland, which would in the future allow to realise the benchmark analyses in the field of international steel market. The detailed goals are: to determine the accident level in metallurgical sector in Poland basing on statistical data with accident severity and frequency rates (general and partial rates) and to determine the level of statistical dependence between the number of accidents and the demographic characteristics of victims. The statistical data gathered in the article provide information on metallurgical sector in Poland.

The main goal of the article (paper) is statistical analysis of safety at work in the metallurgical (steel) industry in Poland. The steel industry in Poland is a key industry in the technology industry, and its share is $2 \%$ of GDP. The work consists of the part covering literature review in which reference is made to the general problem of accidents in the aspect of key factors (the consequences of accidents at work), and the practical part - the analysis of accident indicators in the analyzed sector in 2009-2015.

\section{Literature Review}

The work accident is an accident that occurred suddenly, was caused by an external rate, occurred due to the work performed and resulted in injury or death of the employee (Lis \& Nowacki, 2005; Szlazak \& Szlazak, 2012; Malysa et al., 2016; Malysa et al., 2017). The definition of the accident is not identical in all countries. The descriptors of the accident are: suddenness and the external cause. The differences relate to the consequences of the accident, i.e.: damage, injury or loss. There are three variants of results: the accident as an injury, the accident as an injury together with the preceding situation, the injury as a result of the accident. The differences relate also to the accident consequences assessment, which include, among other things, the following: physical injuries, material damage, disruptions in manufacturing and the damages to the social image of the company (Szlazak \& Szlazak, 2012).

For the statistical purposes, the accident rates (general, partial) are used in accident analysis. They allow to compare the safety level in various branches and companies in chosen periods of time. The accident rate is a sum of accidents occurred in the chosen time period, most frequently in the calendar year. Not always the number of accidents completely depicts the safety level in the examined area, thus some additional rates (of severity and frequency of the accidents) are used (Krause, 2014; Lis \& Nowacki, 2005). The frequency rates $\left(\mathrm{W}_{\mathrm{z}}\right)$ describe the probability of accident occurrence. It is described as the quotient of the workers injured as a result of the accident (W) and the number of employed or working people (Z). Analogically, this rate is applied for severe accidents $\left(\mathrm{W}_{\mathrm{zc})}\right.$ (2) and fatal accidents $\left(\mathrm{W}_{\mathrm{zs}}\right)$ (3). For relation between the number of accidents and the production volume, we use the accident frequency rate for the certain volume of production $\left(\mathrm{W}_{\mathrm{p}}\right)$. It is expressed as a quotient of the total number of persons injured in work accidents (W) and the production volume in $\mathrm{Mg}(\mathrm{P})(4)$.

The severity rates $\left(\mathrm{C}_{\mathrm{w}}\right)$ inform on the severity of the accidents or show the average number of work-days that is lost as a result of a single accident. For the purpose of this article this rate was described as a quotient: total work absence caused by the accidents $\left(D_{s}\right)$ and the number of persons injured in accidents $(\mathrm{W})$ - the relation 5 or the number of work-days lost due to the work accidents $\left(D_{s}\right)$ to the difference between the total number of injured persons (W) and fatal accidents $\left(\mathrm{W}_{\mathrm{s}}\right)$ - the relation 5 .

$$
\begin{gathered}
W_{z}=\frac{W}{Z} \cdot 10^{3} ; W_{z c}=\frac{W_{c}}{Z} \cdot 10^{5} ; W_{z s}=\frac{W_{s}}{Z} \cdot 10^{5} \\
W_{p}=\frac{W}{P} \cdot 10^{6} ; C_{w}=\frac{D_{s}}{W} ; C_{w-s}=\frac{D_{s}}{W-W_{s}}
\end{gathered}
$$


For the purpose of this article, there were determined the severity and frequency rates described with mathematical relationships (1 to 6) which allowed to perform the ratio analysis of accidents at work. In literature, issues (Lis \& Nowacki, 2005; Malysa, 2019; Szlazak \& Szlazak, 2012; Ceylan, 2012) and business practice accident rates are most often used due to the possibility of comparing the number of accidents in various industries, e.g. mining, metallurgy industry (Malysa, 2019; Krause, 2015). The assessment of the rate indicator also allows to compare the number of accidents in a given enterprise. The authors of the study, analysing bibliometric databases, did not register conducting accident tests in the metallurgical sector in Poland, therefore they undertook to fill the gap in the analysed field. In the bibliometric databases i.e. SCOPUS, Web of Science, Google Schoolar database, publications are devoted to the analysed accident problem in the metallurgical industry, e.g. Brazil, Turkey or India (Perciliano \& Silvano, 2019; Ujwala, et al., 2015, Ceylan, 2012 Saha, et al., 2007), however, there is no analysis for the metallurgy industry in Poland.

Diversification of the method of measuring accident rates in individual industry sectors depends on the scope of conducted research and the degree of their detail and may be based on both quantitative and qualitative data.

\section{Methodology of the Performed Analysis}

The performed analysis of the accidents that took place in Poland (metallurgical industry) in years 2009-2015 was divided into three stages:

- the first one presents the data relating to the employment structure, the number of the accidents, the types of the accidents, the number of work absence days based on the data provided by the Central Statistics Office in Poland;

- the second stage presents the accident rates (severity and frequency);

- the third stage presents the analysis of accidents number in relation to the demographic characteristics.

The presented model of the accident analysis in the metallurgical sector (figure 1) consisted in a set of statistical data related to the accidents at work, allowing to determine the accident rates (stage 2). The last stage (third) consisted in the relation of the gathered accidents with the age and experience of workers injured in accidents. The applied methodology allowed to achieve the utilitarian objective of the article.

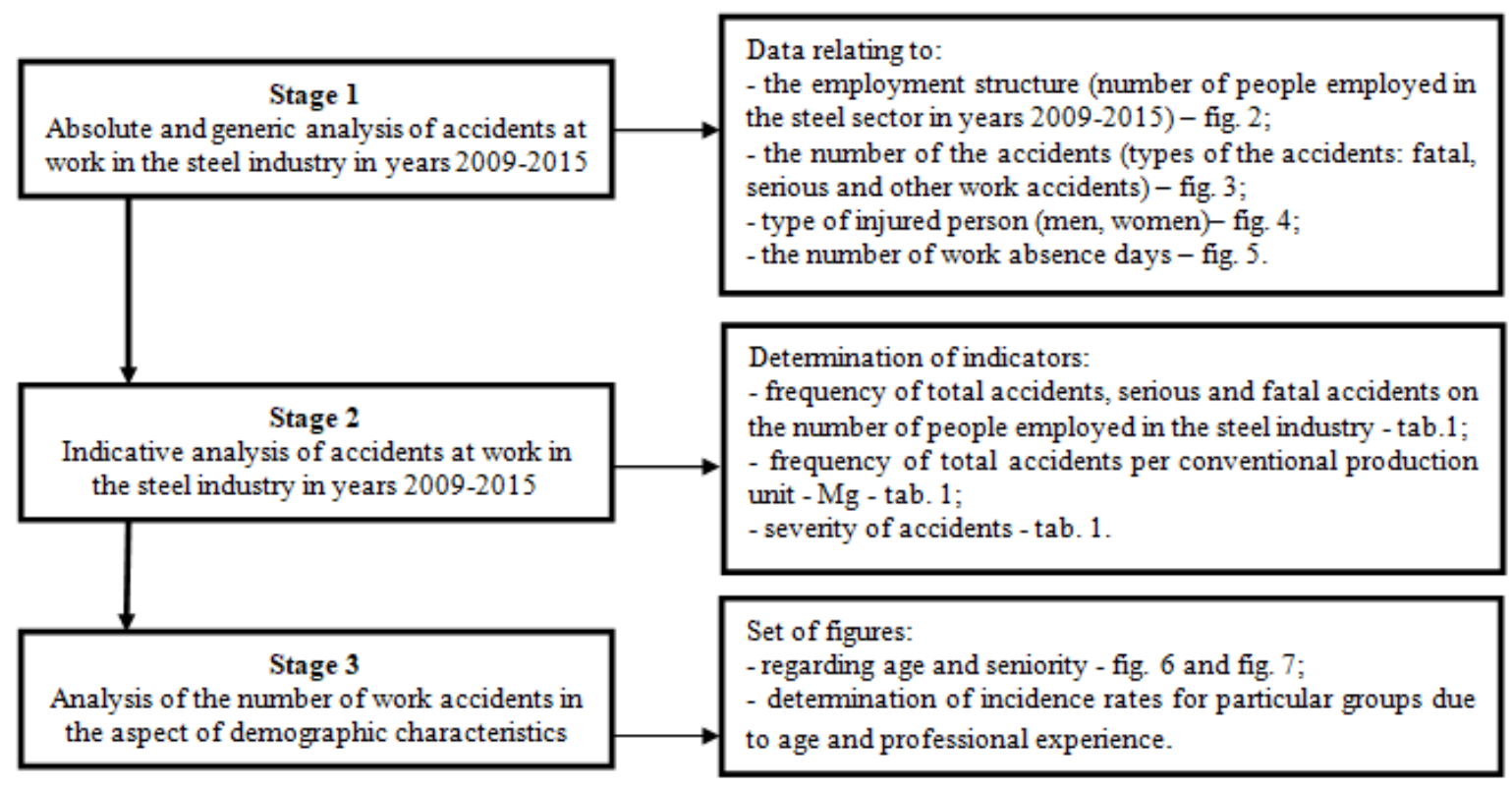

Figure 1. Methodology of the Accident Analysis in the Metallurgical Sector

Source: own elaboration

\section{Analysis of Accidents at Work in the Steel Industry in Poland}

The article analyses the accident rate in the metallurgical sector in Poland in years 2009-2015. The objective of the analysis was to determine the dependence between the number of the accidents and the demographic characteristics of the injured workers. The analysis was done using the data published by the Central Statistics Office - related to the accidents that took place in steel manufacturing companies in Poland. Due to the time period taken into account (eight years), the following analysis had a mid-term characteristic (more than five years). The subject of the performed analysis consisted in the set of numerical accident characteristics, according to the demographic characteristics of injured workers: sex, age, professional experience.

The metallurgical industry in Poland employs currently over twenty thousand people. In the analyzed period there was observed a decreasing employment trend in the researched area (figure 2). This decrease is a result of employment reduction and the adaptation of work efficiency (counted as a production volume per 1 employee) to the international levels (Gajdzik, 2013b, 
2013c). In the year 2009, 26.3 thousand people were employed, while in 2015 it was 20.4 thousand. This decrease is observed to this day. It is expected that in next 3 years the employment rate will fall to the level of 15.6 thousand workers in the analyzed sector in Poland (Gajdzik \& Szymszal, 2015).

The performed analysis of the number of the accidents that occurred in metallurgical industry in Poland was aimed to: change the accident level, its growth rate and in case of cause and effect conclusion, to describe the relations that exists between the occurred accidents and injured workers (their age, sex and professional experience). The fundamental part of the research performed was the analysis of the accident rates value change in the reference period (accident severity and frequency rates). For the purpose of this work, the following analyses of work accidents were performed: the absolute (stage 1), the indicative (stage 2) and generic (stage 3).

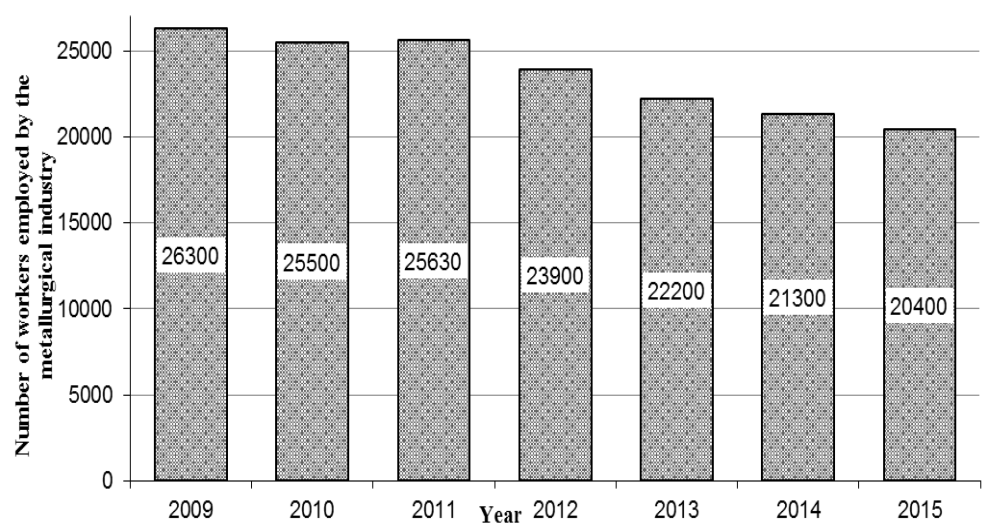

Figure 2. Employment Structure in the Metallurgical Sector in Poland in Years 2009-2015

Source: own elaboration on the base of statistical data

\section{Absolute Analysis of Work Accidents in the Steel Industry in Poland}

The absolute analysis of work accidents consists in the comparison of accident measures, i.e. the number of the accidents occurred with regard to the severity of results (fig. 3), sex of the injured workers (fig. 4) and the number of work absence days (figure 5).

The conclusions of the work accidents analysis performed in the metallurgical sector in years 2009-2015 are: the workers were most of the time injured in minor accidents - not resulting in the long-term work absence. The biggest number of minor accidents 1109 was registered in 2011, while the lowest number 887 was registered in 2014. In the analysed period of time there is observed a decrease in the number of minor accidents in years 2012-2015 in comparison with 2009-2011. The number of these accidents clearly shows a decrease tendency (Gajdzik \& Ocieczek, 2015). This decrease may be connected to the currently observed changes: the declining number of workers and the results of the safety management systems introduced in metallurgical companies (Gajdzik 2013a; Gajdzik \& Grzybowska, 2013) - (figure 1).

The key roles (from the social and economic costs point of view) play the accidents that result in long-term absence of the worker, or his death. The biggest number of severe accidents in metallurgical industry was registered in 2013, when the number of such accidents was 18 . As to the fatal accidents, the number of such incidents changed: 2 fatal accidents in 2012 and 2014, 5 such incidents in 2009 and none in 2015.

Among the workers injured in the metallurgical industry, most frequently they are males. This is a result of the employment structure, i.e. men are the dominant group of people employed in the metallurgical industry. Basing on the analysis of the data gathered (figure 4.), it is visible that since 2012 a decrease in the number of accidents among women and men in comparison to the years 20092011. The changes observed in the accident statistic of women and men are a result of the decreasing number of workers employed in the metallurgical industry in Poland, but may also be a result of improved workplace safety.

The occurring accidents result in work absence of employees, who sometimes are not able to return to work (severe accidents). The biggest number of work absence days (55288) was registered in metallurgical industry in Poland in 2011. This number of days results from the number of accidents - 1127. In the year 2012 there was registered a drop of absence days among metallurgical companies' employees in Poland, what may also be explained by the lower number of accidents. However, since 2013 there is again observed an increase of work absence days, what may be explained by the number of severe and fatal accidents that generate the work absence increase. The changing work absence of employees in the metallurgical sector in Poland in years 2009-20015 is presented in the graphic (figure 5). 


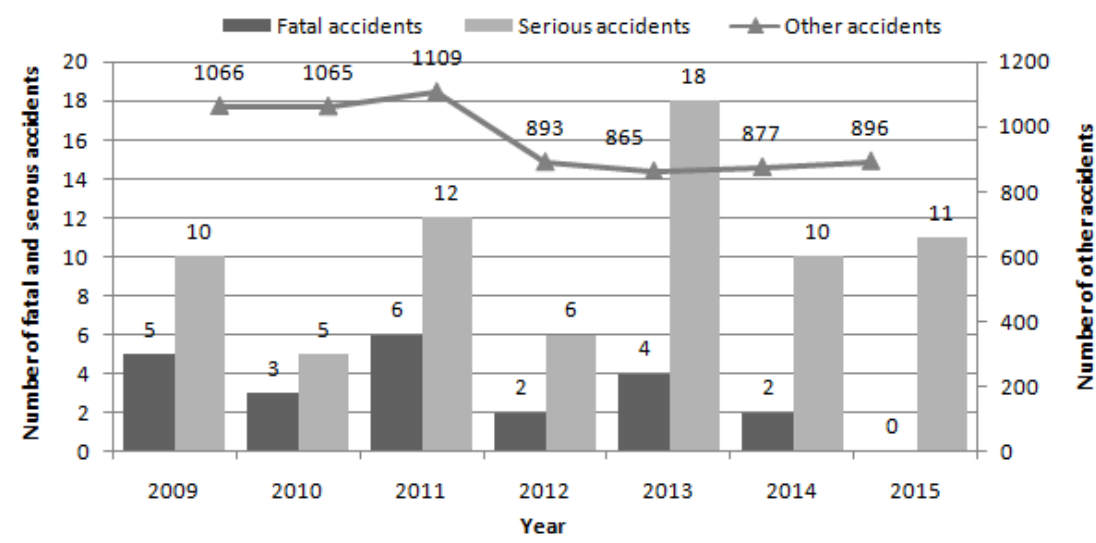

Figure 3. Number of Fatal, Serious and Other Work Accidents in the Metallurgical Industry in Poland Source: own elaboration on the base of statistical data

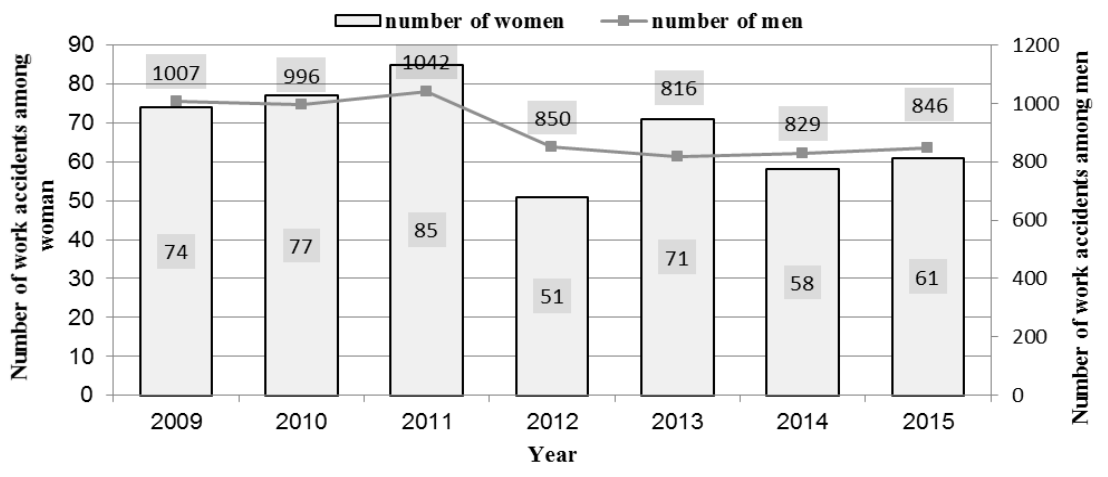

Figure 4. Number of Work Accidents among Women and Men in the Metallurgical Industry in Poland Source: own elaboration on the base of statistical data

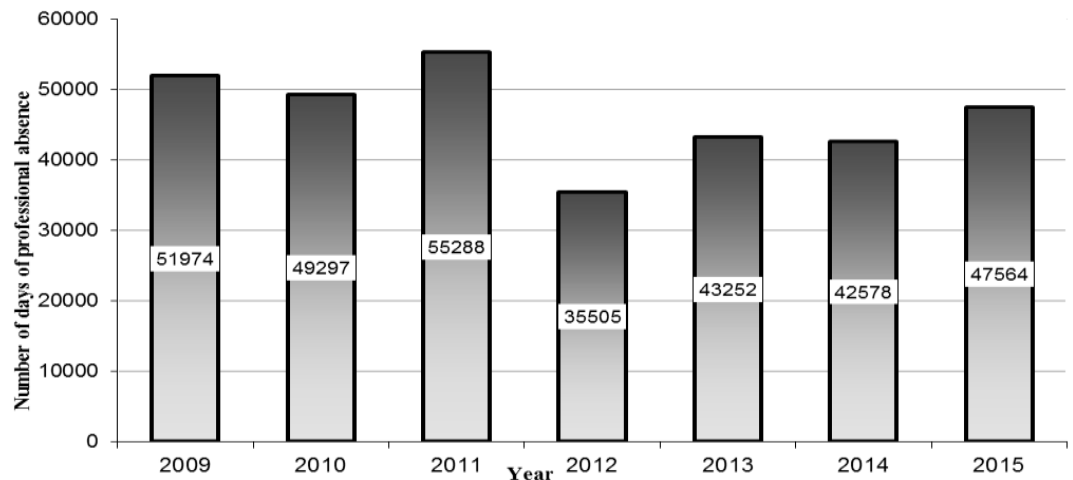

Figure 5. The Number of Days of Professional Absence of Employees in the Metallurgical Industry in Poland

Source: own elaboration on the base of statistical data

\section{The Ratio Analysis of Work Accidents in the Steel Industry in Poland}

The ratio analysis is based on the comparison of the frequency and severity rates of the accidents, determined with the relations $1-6$. In order to determine these rates, the data from the stage 1 was used - the analysis performed. The indicative analysis was completed with data related to the steel production volume in Poland, which allowed to present the changes in the number of accidents in relation to the volume of produced steel. The results obtained are presented in the table 1 . In order to perform the analysis of accidents differentiation, the average value of each rate, its minimum and maximum value, the average deviation and the variability coefficient were set down. For the article, the following interpretation of the variability coefficient was used: low variability (below $25 \%$ ), moderate variability (between $25 \%$ and $45 \%$ ), high variability (between $45 \%$ and $65 \%)$, very high variability $(65 \%-100 \%)$. The determined characteristics of the descriptive statistic were presented in the table 2 . 
Values of Accident Rates in the Metallurgical Industry in Poland (2009-2015)

\begin{tabular}{|c|c|c|c|c|c|c|c|}
\hline Adopted measures of accidents & 2009 & 2010 & 2011 & 2012 & 2013 & 2014 & 2015 \\
\hline Total accident rate indicator $\left(\mathrm{W}_{\mathrm{z}}\right)$ & 41.1 & 42.1 & 44.0 & 37.7 & 40.0 & 41.7 & 44.5 \\
\hline Frequency rate indicator of severity accidents $\left(\mathrm{W}_{\mathrm{zc}}\right)$ & 38.0 & 19.6 & 46.8 & 25.1 & 81.9 & 46.9 & 53.9 \\
\hline Frequency rate indicator of fatal accidents $\left(\mathrm{W}_{\mathrm{zs}}\right)$ & 19.0 & 11.8 & 23.4 & 8.4 & 18.0 & 9.4 & 0.0 \\
\hline Frequency rate indicator for the conventional production value $\left(\mathrm{W}_{\mathrm{p}}\right)$ & 151.6 & 134.2 & 128.4 & 107.9 & 111.6 & 103.9 & 98.6 \\
\hline $\begin{array}{l}\text { Frequency rate indicator of severity accidents for the conventional } \\
\text { production value }\left(\mathrm{W}_{\mathrm{pc}}\right)\end{array}$ & 1.4 & 0.6 & 1.4 & 0.7 & 2.3 & 1.2 & 1.2 \\
\hline $\begin{array}{l}\text { Frequency rate indicator of fatal accidents for the conventional } \\
\text { production value }\left(\mathrm{W}_{\mathrm{ps}}\right)\end{array}$ & 0.7 & 0.4 & 0.7 & 0.2 & 0.5 & 0.2 & 0.0 \\
\hline Accident severity rate $\left(\mathrm{C}_{\mathrm{w}}\right)$ & 48.1 & 45.9 & 49.1 & 39.4 & 48.8 & 47.9 & 52.4 \\
\hline Accident severity rate reduced by the number of fatal accidents $\left(\mathrm{C}_{\mathrm{w}-\mathrm{s}}\right)$ & 48.3 & 46.1 & 49.3 & 45.9 & 49.0 & 48.0 & 52.4 \\
\hline
\end{tabular}

Source: own elaboration on the base of statistical data

Characteristics of Descriptive Statistics for Accident Rates in the Metallurgical Industry in Poland

\begin{tabular}{|c|c|c|c|c|c|}
\hline Adopted measures of accidents & Min & Max & Average & $\begin{array}{l}\text { Deviation } \\
\text { standard }\end{array}$ & $\begin{array}{l}\text { Coefficient of } \\
\text { variation }\end{array}$ \\
\hline Total accident rate indicator $\left(\mathrm{W}_{\mathrm{z}}\right)$ & 37.7 & 44.5 & 41.6 & 2.3 & 5.6 \\
\hline Frequency rate indicator of severity accidents $\left(\mathrm{W}_{\mathrm{zc}}\right)$ & 19.6 & 81.1 & 44.5 & 20.3 & 45.6 \\
\hline Frequency rate indicator of fatal accidents $\left(\mathrm{W}_{\mathrm{zs}}\right)$ & 0.0 & 23.4 & 12.9 & 7.9 & 61.5 \\
\hline Frequency rate indicator for the conventional production value $\left(\mathrm{W}_{\mathrm{p}}\right)$ & 98.6 & 151.6 & 119.5 & 19.2 & 16.1 \\
\hline $\begin{array}{l}\text { Frequency rate indicator of severity accidents for the conventional } \\
\text { production value }\left(\mathrm{W}_{\mathrm{pc}}\right)\end{array}$ & 0.6 & 2.3 & 1.2 & 0.5 & 43.2 \\
\hline $\begin{array}{l}\text { Frequency rate indicator of fatal accidents for the conventional } \\
\text { production value } W_{\mathrm{ps}} \text { ) }\end{array}$ & 0.0 & 0.7 & 0.4 & 0.3 & 65.7 \\
\hline Accident severity rate $\left(\mathrm{C}_{\mathrm{w}}\right)$ & 39.4 & 52.4 & 47.4 & 4.0 & 8.5 \\
\hline Accident severity rate reduced by the number of fatal accidents $\left(\mathrm{C}_{\mathrm{w}-\mathrm{s}}\right)$ & 45.9 & 52.4 & 48.4 & 2.2 & 4.5 \\
\hline
\end{tabular}

Source: own elaboration on the base of statistical data

The values of the overall accident frequency rate $\left(\mathrm{W}_{\mathrm{z}}\right)$ with regard to the number of metallurgy workers in Poland are characterised with low variability (the variability coefficient of 5.6\%). In years 2009-2011 a small increase of the coefficient was registered (increase from z 41.1 to 44.0). In 2012 this value decreased $-\mathrm{W}_{\mathrm{z}}=37.7$. Such drop was caused by the decrease of the employment rate and the smaller number of work accidents in relations to years 2009 - 2011. In years 2013-2015 there was observed an increase of the rate, accordingly: $\mathrm{W}_{\mathrm{z}}=40.0$ (2013) to $\mathrm{W}_{\mathrm{z}}=$ 44.5 (2015). This increase was a result of greater number of occurred work accidents and the falling number of the employed workers in comparison with the previous years. The frequency rate of the severe accidents in the group of metallurgical workers in Poland $\mathrm{W}_{\mathrm{zc}}$ was characterised with high variability (the variability coefficient $=45.6$ ). It changed from the lowest value $\mathrm{W}_{\mathrm{cz}}=19.6$ (2010) to $\mathrm{W}_{\mathrm{cz}}=$ 81.1 in 2013. The highest value of this rate is a result of the occurred number of severe accidents (18 accidents in 2013). The frequency rate of fatal accidents in the metallurgical industry in Poland is characterised with high variability $(61.5 \%)$. Its lowest value was observed in 2015 , when there were no fatal accidents $\left(\mathrm{W}_{\mathrm{zs}}=0\right)$. The highest value of this rate $\mathrm{W}_{\mathrm{zS}}=23.4$ was registered in 2011. Also, high values of this rate were registered in 2009 $\left(\mathrm{W}_{\mathrm{zs}}=19\right)$ and $2013\left(\mathrm{~W}_{\mathrm{zs}}=18\right)$.

In order to refer the number of accidents to the steel production value, the general accident frequency rates were determined for a steel production unit in Poland, in the analysed period of time. Basing on the analysis of the gathered rate values, there was registered its drop from the highest value $\mathrm{W}_{\mathrm{p}}=151.6$ (year 2009) down to $\mathrm{W}_{\mathrm{p}}=98.6$ (year 2015). The changes in the rate value $\mathrm{W}_{\mathrm{p}}$ despite the increase in the steel production value in Poland are determined by the annual decrease of the employment rate in metallurgy in Poland (figure 1). This rate is characterised by small coefficient of change $(16.1 \%)$.

For severe and fatal accidents (per production unit) this rate is characterised with moderate $(43.2 \%)$ and significant variability $(65.7 \%)$. The values of severe accidents rate are changing from 0.6 (2010) to 2.3 (2013), while the frequency of fatal accidents - from 0.7 (2009, 2011) to the value of 0.0 in 2015 .

The accident severity rate in general $\left(\mathrm{C}_{\mathrm{w}}\right)$ and the severity rate reduced by the number of fatal accidents $\left(\mathrm{C}_{\mathrm{w}-}\right.$ s) are characterised with low variability $(8.5 \%$ and $4.5 \%)$ in steel industry in Poland. The determination of these rates allowed to gather information on the number of workdays lost due to the occurred accidents at work. The severity rate values are changing from $\mathrm{C}_{\mathrm{w}}=39.4$ (2012), $\mathrm{C}_{\mathrm{w}-\mathrm{s}}=45.9$ (2019) to $\mathrm{C}_{\mathrm{w}}, \mathrm{C}_{\mathrm{w}-\mathrm{s}}=52.4$ (2015). It is the highest value of this rate in the analysed time period.

\section{The Dependence between the Number of Work Accidents and the Demographic Characteristics of the Injured in Accidents}

The performed absolute, generic and ratio analyses of work accidents in metallurgical industry was related to the number of accidents, work-absence days and steel production volume in Poland. In relation to the above mentioned data, the occurred accidents were related to the 
demographic characteristics of the injured workers. In order to realise the third stage of the methodology, there were determined the accident frequency rates in relation to the age range of the injured person and work experience, which were presented graphically in figure 6 and figure 7.

For accident frequency rates registered in metallurgical industry in Poland there were determined the characteristics of the descriptive statistics (table 3 and table 4) allowing to realize the goal of the article, which was to determine the level of statistical relations between the accident rate and the demographic characteristics of the injured persons (the victims of the accidents).

Basing on the performed analysis of the accidents occurred in particular age groups - figure 6 it was concluded that the age groups: 20-29, 30-39 and 40-49 are the groups that are affected by the accidents most often. The occurring accidents are characterised with low variability - the variability rates were respectively $12.2 \%$, $9.5 \%, 15.8 \%$ (table 3), which means that the number of such accidents is very similar every year. The reasons for accidents in these groups may be: lack of experience, routine and familiarization with existing dangers. Basing on the data analysis it was stated that employers should pay attention to these workers, realising the actions aimed at work safety increase.
The lowest accident number is registered in the groups of workers of 19 or less years old and 60-65 years old or more. The occurred accidents in the group of 19 or less years old are characterised with moderate variability (29.2\%), it means that in the analysed time period the number of such accidents was similar (on average, 4 accidents each year). Also, in the group of 65 or more years old it was not registered a great number of work accidents, but the variability of such accidents is very large $(76.4 \%)$ which is a result of the fact that in 2013 there were no accidents registered in this group. The issue of accidents at work, taking into account the age of workers, was also the subject of Saha, et al., 2007 research. The author studied three groups in metallurgical sector: less than 30 years old, 3049 and 50 and over. The result of the association of accidents with the age of employees was confirmation that the highest risk group is employees 30-39 years (39 persons). In our studies, age groups were more specific. In our study, age groups were more specific - nine groups were used. In our study, age groups were more specific nine groups were used. So the accuracy of our analysis was greater compared to Saha et al., 2007 research. Comparing our results and Saha et al., 2007 results, the similar age groups were found to be the highest risk groups. This group in Saha et al., 2007 was 30-49 years old, and in our studies this group was 30-39. A collective summary of the analyzed data is presented graphically in figure 9 .

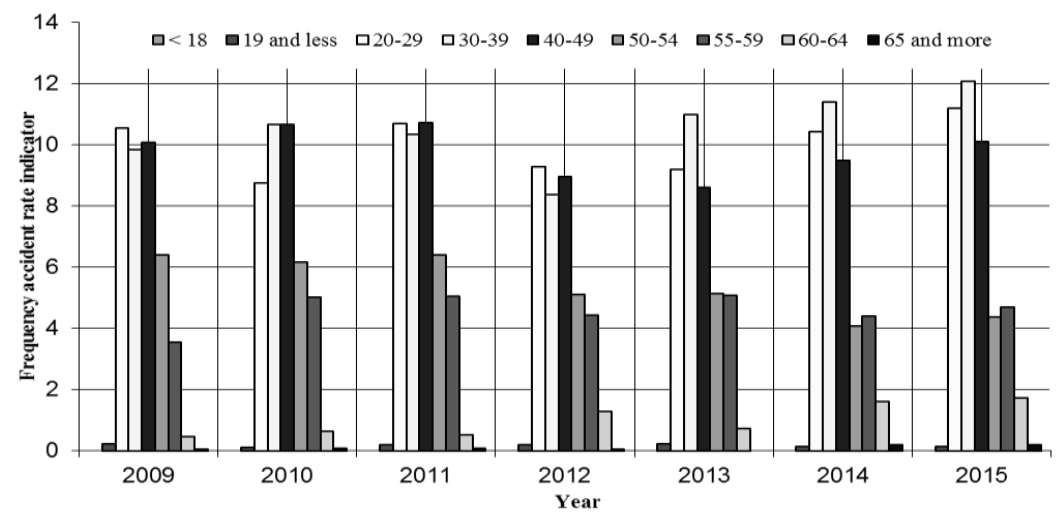

Figure 6. Frequency Rate Indicator of Accidents for Individual Age Groups in the Metallurgical Industry in Poland Source: own elaboration on the base of statistical data

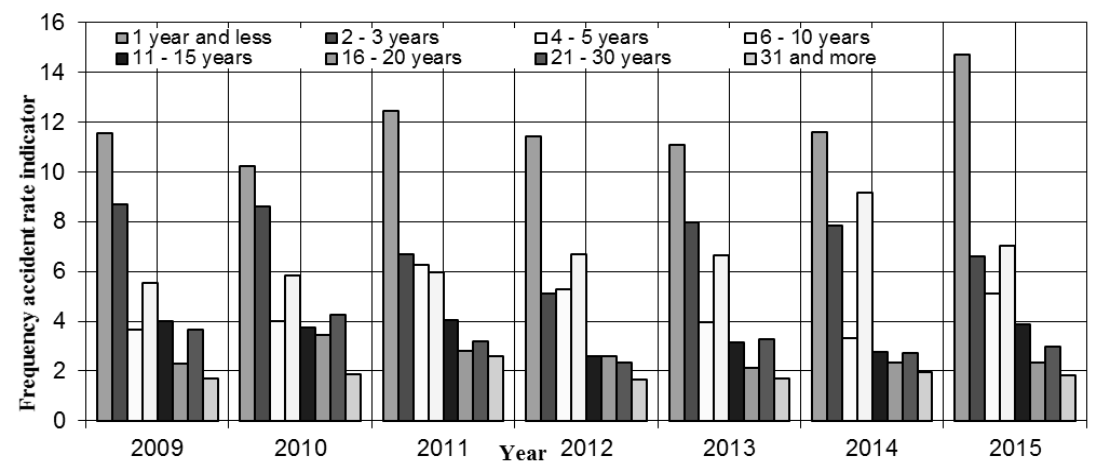

Figure 7. Seniority of Injured in Accidents in the Metallurgical Industry in Poland Source: own elaboration on the base of statistical data 
Characteristics of Descriptive Statistics for Accident Rates (Age Groups) in Metallurgical Industry in Poland

\begin{tabular}{|c|c|c|c|c|c|}
\hline Range of age & Min & Max & Average & Deviation standard & Coefficient of variation \\
\hline$<18$ & - & - & - & - & - \\
\hline 19 and less & 0.1 & 0.2 & 4.3 & 1.3 & 29.2 \\
\hline $20-29$ & 8.7 & 11.2 & 235.7 & 28.2 & 12.2 \\
\hline $30-39$ & 8.4 & 12.1 & 247.0 & 23.6 & 9.5 \\
\hline $40-49$ & 8.6 & 10.7 & 232.1 & 36.8 & 15.8 \\
\hline $50-54$ & 4.1 & 6.4 & 128.7 & 34.6 & 26.9 \\
\hline $55-59$ & 3.5 & 5.1 & 108.4 & 15.5 & 14.3 \\
\hline $60-64$ & 0.5 & 1.7 & 22.4 & 11.4 & 46.3 \\
\hline 65 and more & 0.0 & 0.2 & 1.5 & 1.5 & 76.4 \\
\hline
\end{tabular}

Source: own elaboration on the base of statistical data

In order to determine what was the work experience of the people that were affected by the accidents at work most often there were determined the frequency rates in relation to the work experience (figure 7). Thanks to the analysis of work experience of the people employed in metallurgical industry it was stated that most often the accident victims were working less than one year. The lowest probability of accident was observed in the group of people working over 16 years. The accident frequency rates for the first group are characterised with low variability $(9.6 \%)$ which means that the number of such accidents is similar. Comparing the result of our analysis with the Saha et al., 2007 study, similar results were obtained. Saha et al., 2007 states that the most at-risk group are employees with seniority (job duration years) up to 5 years. Our seniority intervals at steel mills are more detailed (eight compartments) and after adding the first, second and third intervals (seniority up to 5 years) we received 3918 and this was our largest range, i.e. we got the same test results as Saha et al., 2007. As the professional experience of workers in steel mills increases, the number of accidents decreases, as confirmed by our and other studies (Saha et al., 2007). A collective summary of the analyzed data is presented graphically in figure 10 .

Table 4

Characteristics of Descriptive Statistics for Accident Rates (for Seniority) in Metallurgical Industry in Poland

\begin{tabular}{|c|c|c|c|c|c|}
\hline Seniority & Min & Max & Average & Deviation standard & Coefficient of variation \\
\hline One year and less & 10.2 & 14.7 & 14,7 & 1.4 & 9.6 \\
\hline $2-3$ years & 5.1 & 8.7 & 6.6 & 1.3 & 19.6 \\
\hline $4-5$ years & 3.3 & 6.2 & 5.1 & 1.0 & 20.6 \\
\hline $6-10$ years & 2.6 & 9.2 & 7.0 & 1.2 & 17.2 \\
\hline $11-15$ years & 2.6 & 4.1 & 3.9 & 0.6 & 15.7 \\
\hline $16-20$ years & 2.1 & 3.5 & 2.4 & 0.5 & 19.2 \\
\hline $21-30$ years & 2.3 & 4.3 & 3.0 & 0.6 & 21.0 \\
\hline 31 and more & 1.7 & 2.6 & 1.8 & 0.3 & 17.3 \\
\hline
\end{tabular}

Source: own elaboration on the base of statistical data

Basing on the information gathered (table 3 and table 4), we may conclude that most often the accident victims are young persons of short work experience (up to three years). The accident rate increase is also observed among the experienced workers, employed between 2-15 years. The high number of accidents may be a result of a fact that such workers got used to the existing dangers and the work they perform became a routine. The decreasing trend is observed among workers having more than 16 years of experience.

In relation to the adopted age ranges (figure 6 , table 3 ) in fig. 8 it was presented the age structure (percentile) of workers employed in the metallurgical industry. According to the gathered data (figure 8) the least numerous professional group consists of workers less than 19 years old (c.a. $1 \%)$. Also, the lowest number of accidents is registered in this group if compared to all other age ranges. The workers of 20-29 years old make c.a. $8 \%$ of persons employed in metallurgical industry, however the highest number of accidents is registered in this particular group. These are mainly the workers at the beginning of their professional career. The dominant group among the employed people consists of workers of 30-54 years old. They make $77 \%$ of the total number of employees. High numbers of accidents at work are also registered in this group. Approximately $13 \%$ are employees aged 55-59, while approx. $13 \%$ employees aged 60 and more $(1 \%)$. These groups consist of people on management positions and qualified workers in the period of protection. Less number of accidents is registered in this group (in comparison with groups of 20-54 years old). 


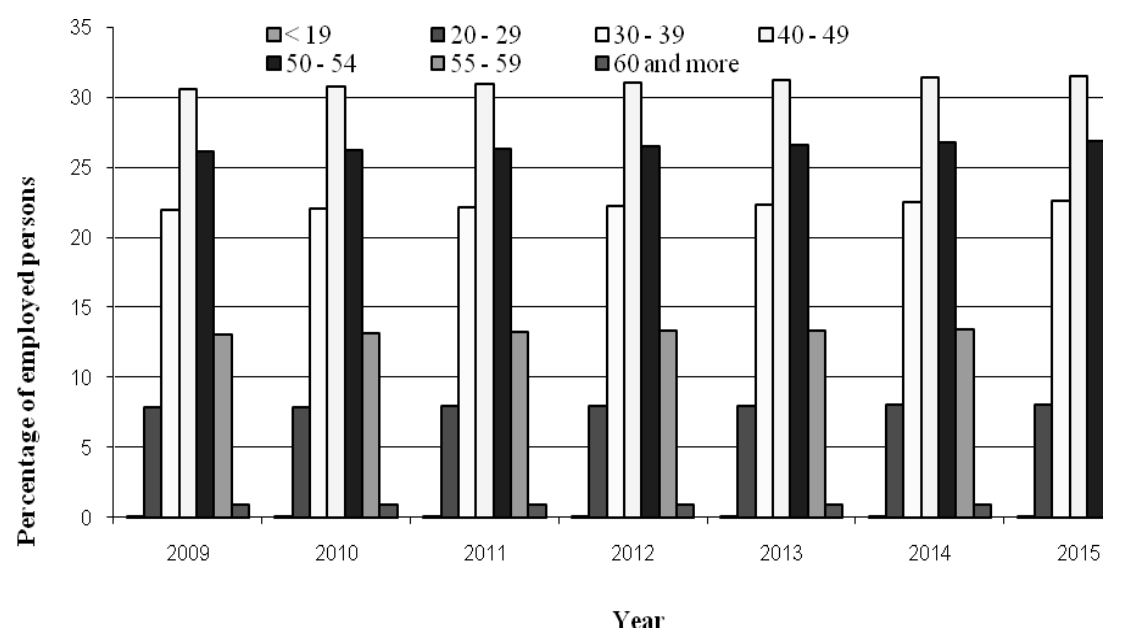

Figure 8. The Age Structure of People Employed in the Metallurgical Industry in Poland Source: own elaboration on the base of statistical data

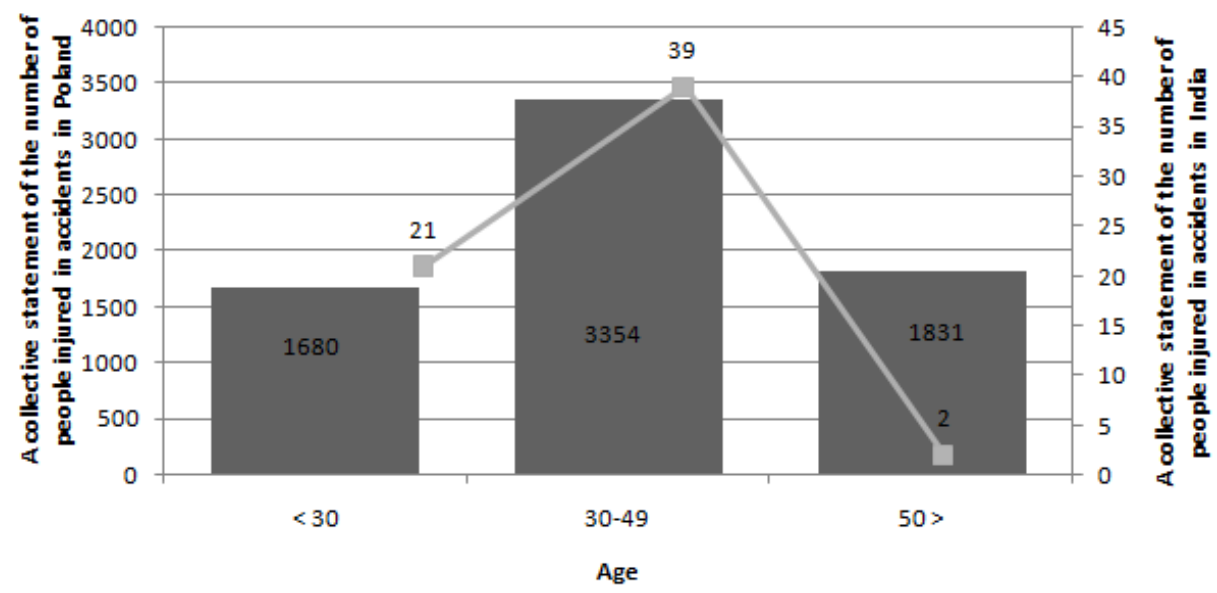

Figure 9. A Collective Summary of the Analyzed Data on the Age of the Persons Injured in Accident at Work

Source: own elaboration on the base of statistical data and Saha et al., 2007

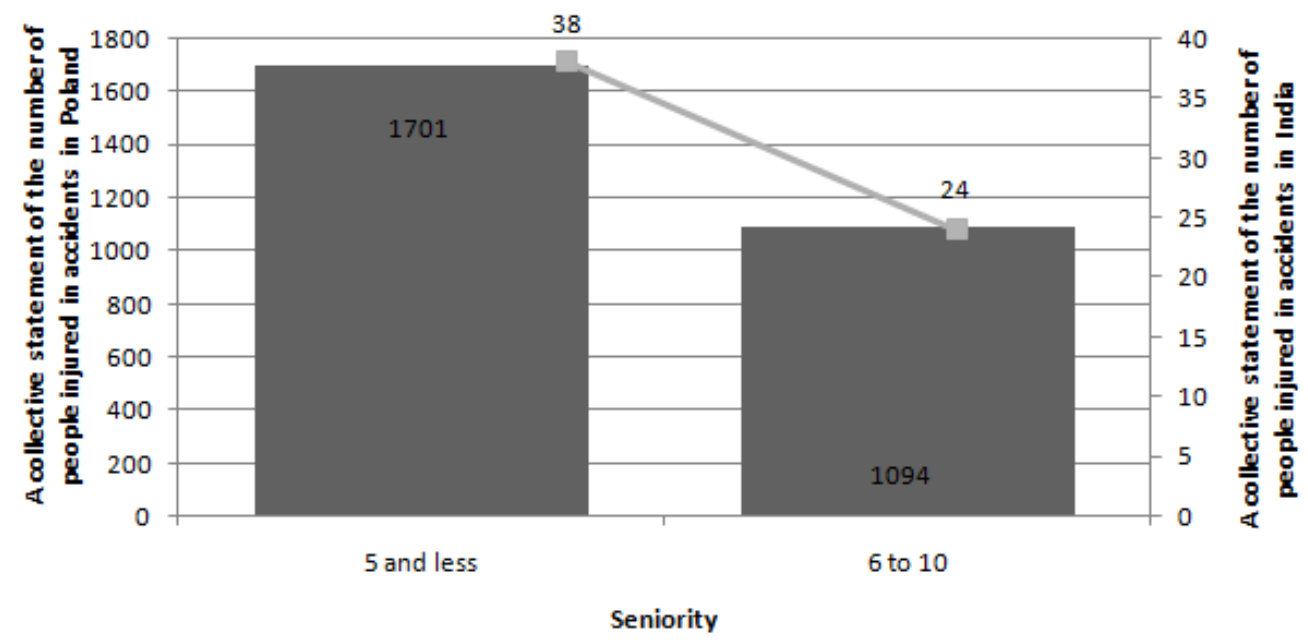

Figure 10. A Collective Summary of the Analyzed Data on the Seniority of the Persons Injured in Accident at Work Source: own elaboration on the base of statistical data and Saha et al., 2007 
The performed accident rate analysis in the metallurgical industry allowed to formulate the following conclusions:

- the accident frequency rate value in general was characterized with low variability $(5.6 \%)$, a decrease in $2012\left(\mathrm{~W}_{\mathrm{z}}=37.7\right)$ and an increase in $2015\left(\mathrm{~W}_{\mathrm{z}}=44.5\right)$,

- the severe accident frequency rate was characterized with high variability $(45.6 \%)$. The medium rate value in the researched period of time was 44.5. It was concluded that in 2013 its significant upward trend was registered $\left(\mathrm{W}_{\mathrm{zc}}=81.9\right)$ in relation to the years 2009-2012 and 20142015:

- the fatal accident frequency rate was characterized with high variability $(61.5 \%)$, the medium rate value in the researched period of time was 12.9,

- the accident frequency value per a single unit of production was characterized with low variability $(16.1 \%)$, while the frequency rates of severe and fatal accidents were accordingly moderate $(43.2 \%)$ and very high $(65.7 \%)$. These rates are characterized with monotonicity (increase, decrease),

- the accident severity rates value were characterized with low variability ( $8.5 \%$ and $4.5 \%)$, the medium values of these rates were accordingly 47.4 and 48.4 .

\section{Conclusion}

The presented work consists of theoretical and practical parts (accident rate statistical analysis). In the theoretical part the general aims of the measurement of the accident rate in the metallurgical industry are presented (along with the instruments). This part has inspired the authors to work out the three-stage (three-segment) methodology of accident rate study - fig. 1 . The proposed methodology consisted of: the absolute and generic analysis performance (stage 1), the ratio analysis (stage 2), and the analysis of accidents at work in relation to the demographic characteristics (stage 3). The presented methodology may be used for benchmark analysis in relations to the accident rates globally. It may also be implemented in the accident analysis of other industry branches.

The determined accident rates in the metallurgical industry were related to the demographic characteristics of the victims. Basing on the analysis performed, it was concluded that most often the victims of the accidents are workers of 20-49 years old. The age of workers is associated with work experience of victims, which results in a fact that most often the people injured in the accidents have work experience of one year or less, but also workers which work experience is not longer than 3 years. Therefore, the employers should implement the actions resulting in a raise of work safety awareness in these groups, e.g. training at workplaces, visual information about existing threats, propagating pro-safe activities by top management.

Accident studies conducted for the metallurgical industry in Poland in comparison with available scientific works on accidents in other countries (Perciliano et al., 2019; Saha et al., 2007; Ujwala et al., 2015) may constitute an important element from the point of view of analyses related to the selection of preventive solutions, as well as assessment of the state of occupational health and safety in individual European or world countries. The conducted analyses carried out may contribute to drawing conclusions related to the assessment whether the occurring accident events concern the same groups in terms of their age, sex or seniority (Saha et al., 2007). The analyses presented in the study will form the basis for further research. The authors are preparing a study devoted to the prognostic analysis of accident rates in the analysed sector, which will be the basis for developing change scenarios in the field of medium-term planning (three years). Analyses carried out in this way will determine whether the age range of employees (20-49 years) resulting in a high number of accidents in the analysed sector will also be a potential threat in the future. In the reference to the research conducted by (Saha et al., 2007), it can be noted that the group aged 30-49 is similarly the group for which the greater number of accidents at work is recorded. The differences, however, are in the numbers of registered events due to the employment structure. In particular, account should be taken of the fact that Generation X (55 and more) will profit from retirement benefits in the coming years, and Generation Y (35 and more) and $\mathrm{Z}$ (20 to 30 years) will dominate in manufacturing companies (Gajdzik \& Szymszal, 2015). Therefore, it is worth conducting further research whether the selected age group will still be included in the group potentially generating accidents at work.

\section{References}

Brown, K.A, Willis, P.G., \& Prussia, G.E. (2000). Predicting safe employee behavior in the steel industry: Development and test of a sociotechnical model. Journal of Operations Management, 18, 445-465. Available from internet: http://citeseerx.ist.psu.edu/viewdoc/download?doi=10.1.1.537.6045\&rep=rep1\&type=pdf. https://doi.org/10.1016/S0272-6963(00)00033-4

BS OHSAS 18001:2007 Occupational health and safety assessment series.

Carrillo JA., Guadix J., \& Onieva L. (2012). Safety management models in manufacturing companies. 6th International Conference on Industrial Engineering and Industrial Management. XVI Congreso de Ingeniería de Organizacion. Vigo, July 18-20, 603-610. Available from internet: https://dialnet.unirioja.es/servlet/articulo?codigo=4236888.

Ceylan, H. (2012). Analysis of occupational accidents according to the sector in Turkey. Gazi University Journal of Science, 25, 909-918. Available from internet: https://dergipark.org.tr/en/download/article-file/83575. 
Council Directive of 12 June 1989 on the introduction of measures to encourage improvements in the safety and health of workers at work. Available from internet: https://eur-lex.europa.eu.

Cox, S. J., \& Cheyne, A. J. T. (2010). Assessing safety culture in offshore environments. Safety Science, 34, 111-129. https://doi.org/10.1016/S0925-7535(00)00009-6

Cox, S., \& Cox, T. (1996). Safety Systems and People (Oxford: Butteroworth-Heimemann).

Cox, S., \& Flin, R. (1998). Safety culture: Philosopher's stone or man of straw? Work \& Stress, 12 (3), $189-201$. https://doi.org/10.1080/02678379808256861

Furman, J., Kuczynska-Chalada, M., \& Poloczek, R. (2018) Improvement of production processes with the use of lean manufacturing tools. MAPE 2018, vol. 1, 529-535. https://doi.org/10.2478/mape-2018-0067

Gajdzik, B. (2013a). The road of Polish steelworks towards market success - changes after restructuring process. Metalurgija, 52 (3), 421-424. Available from internet: https://hrcak.srce.hr/95792.

Gajdzik, B. (2013b). Diagnosis of employee engagement in metallurgical enterprise. Metalurgija, 52 (1), $139-142$. Available from internet: https://hrcak.srce.hr/86787.

Gajdzik, B. (2013c). World Class Manufacturing in metallurgical enterprise. Metalurgija, 52 (1), 131-134. Available from internet: https://hrcak.srce.hr/86785.

Gajdzik, B., \& Grzybowska, K. (2013). Internal sources of risk in building employees' attitudes of safe work in metallurgical enterprise. Metalurgija, 2 (52), 285-288. Available from internet: https://hrcak.srce.hr/92690.

Gajdzik, B., \& Ocieczek, W. (2015). Soft restructuring process in metallurgical enterprises in Poland. Metalurgija, 54 (3), 729-732. Available from internet: https://hrcak.srce.hr/138299.

Gajdzik, B., Zwolinska, D., \& Szymszal, J. (2015). Behavioural determinants of work accidents and absenteeism in a metallurgical enterprise. Metalurgija, 54 (3), 741-744. Available from internet: https://hrcak.srce.hr/138302.

Gajdzik, B., \& Szymszal, J. (2015). Generation Gap Management in Restructured Metallurgical Enterprises in Poland. International Journal of Management and Economics, 47, 107-120. Available from internet: http://www.sgh.waw.pl/ijme/ .https://doi.org/10.1515/ijme-2015-0031

Glendon, A. I., \& Stanton, N. A. (2000). Perspectives on safety culture. Safety Science, 34, $193-214$. https://doi.org/10.1016/S0925-7535(00)00013-8

Granerud, L., \& Rocha, R. S. (2011). Organisational learning and continuous improvement of health and safety in certified manufacturers. Safety Science, 49, 1030-1039. Available from internet: https://doi.org/10.1016/j.ssci.2011.01.009

Guldenmund, F. W. (2000). The nature of safety culture: a review of theory and research. Safety Science, 34, $215-257$. https://doi.org/10.1016/S0925-7535(00)00014-X

Hola, B., \& Szostak, M. (2017). An Occupational Profile of People Injured in Accidents at Work in the Polish Construction Industry. Procedia Engineering 208, 43-51. https://doi.org/10.1016/j.proeng.2017.11.019

ISO 9001:2015 Quality management systems - Requirements.

ISO 14001:2015 Environmental management systems - Requirements.

ISO 45001:2018 Occupational health and safety management systems. Requirements with guidance for use.

Kim, W. Y., \& Cho, H. H. (2016). Unions, Health and Safety Committees, and Workplace Accidents in the Korean Manufacturing Sector. Safety and Health at Work 7, 161-165. https://doi.org/10.1016/j.shaw.2016.02.005

Koursi, E. M., Mitra, El., S., \& Bearfield, G. (2007). Harmonising safety management systems in the European railway sector. Safety Science Monitor, 11, 1-14.

Krause, M. (2014). Analysis of occupational health and analysis of occupational accident at work. Publishing Silesian University of Technology, 62-64.

Krause, M. (2015). Research of the risk diversification of accident at work illustrated with the example of absolute and ratio analysis form mining industry in Poland. Przeglad Gorniczy, 6, 35-41.

Lis, T., \& Nowacki, K. (2005). Occupational health and safety management in an industrial plant, (p. 181). Gliwice: Silesian University of Technology.

Long, J.S, \& Freese J. (2014). Regression models for categorical dependent variables using Stata. 3rd ed. Texas (US): STATA Press, 507-516.

Malysa, T., Nowacki, K., \& Furman, J. (2016). The risk management methodology in the metallurgical enterprise. 25th Anniversary International Conference on Metallurgy and Materials, Brno, Czech Republic, May 25th - 27th, 2016. Conference proceedings, pp. 1925-1930.

Malysa, T., Nowacki, K., \& Lis, T. (2017). The correlation between structure of employment and accidents at work in metallurgical enterprises. 26th Anniversary International Conference on Metallurgy and Materials, Brno, Czech Republic, May 24th - 26th, 2017. Conference proceedings, pp. 2244-2249. 
Tomasz Malysa, Bozena Gajdzik. Research on Differentiation of Accidents at Work Considering Demographic Features...

Malysa, T. (2019). Work safety during usage, repair and maintenance of machines - a review of work safety in the aspect of accident at work. New trends in Production Engineering, 2, 151-161. https://doi.org/10.2478/ntpe-2019-0080

Markey, R., \& Patmore, G. (2011). Employee participation in health and safety in the Australian steel industry, 19352006. British Journal of Industrial Relations 49, 144-167. https://doi.org/10.1111/j.1467-8543.2009.00756.x

Nielsen, K. J. (2014). Improving safety culture through the health and safety organization: A case study. Journal of Safety Reserarch 48, 7-17. Available from internet: https://doi.org/10.1016/j.jsr.2013.10.003

Nowacki, K. (2019). The impact of implemented management systems on the safety culture of work production. New trends in Production Engineering, 2, 243-252. https://doi.org/10.2478/mape-2019-0024

Perciliano, C. J., \& Silvano, Z. O. (2019). Profile analysis of work accidents in a metallurgical industry of the Zona Da Mata Mineira. International Journal of Engineering Trends and Technology, 67, 124-127. Available from internet: https://www.ijettjournal.org/Volume-67/Issue-11/IJETT-V67I11P219.pdf. https://doi.org/10.14445/22315381/IJETT-V67I11P219

PN-N 18001:2004 Occupational health and safety management systems - Requirements.

PN-N 18002:2011 Occupational health and safety management systems - General guidelines for occupational risk assessment.

PN-N 18004:2001 Occupational health and safety management systems - Audit guidelines.

Saha, A., Kumar, S., \& Vasudevan, D. M. (2007). Occupational injury surveillance: A study in metal smelting industry. Idian Journal Occupational \& Environmental Medicine, 11, 103-107. https://doi.org/10.4103/0019-5278.38458

Santos, G., Barros, S., Mendes, F., \& Lopes, N. (2013). The main benefits associated with health and safety management systems certification in Portuguese small and medium enterprises post quality management system certification. Safety Science, 51, 29-36. https://doi.org/10.1016/j.ssci.2012.06.014

Szlazak, J., \& Szlazak, N. (2012). Occupational health and safety. (pp. 91-92). Cracov: AGH.

Sorensen, J. N. (2002). Safety culture: a survey of the state-of-the-art. Reliability Engineering and Safety 76, $198-204$. Available from internet: https://www.nrc.gov/docs/ML0827/ML082740187.pdf. https://doi.org/10.1016/S09518320(02)00005-4

Ujwala, U. U., Ghruv, Ch. S., \& Padmasree, D. (2015). Occupational injuries in work steel plant at Visakhapatnam. International Journal of Preventive medicine Research, 1, 79-83.

Wallace, M. (1987). Dying for coal: the struggle for health and safety conditions in American coal mining, 1930-1983. Sonic Forces 66, 335-364. https://doi.org/10.1093/sf/66.2.336

Yangho, K., Park, J., \& Park, M. (2016). Creating a Culture of Prevention in Occupational Safety and Health Practice, Safety and Health at Work 7, 89-96. Available from internet: https://doi.org/10.1016/j.shaw.2016.02.002

\section{Author's biography}

Tomasz Malysa $\mathrm{PhD}$ is an assistant professor at the Faculty of Materials Engineering of Silesian University of Technology. He specializes in theoretical and practical issues relating to the occupational health and safety. Tomasz Malysa is the author publications associated with: safety at work, accident analysis, risk analysis, forecasting [ORCID: 0000-0002-9352-0528].

Bożena Gajdzik $\mathrm{PhD}$ is an associate professor at the Faculty of Materials Engineering of Silesian University of Technology (Poland). She specializes in theoretical and practical issues relating to the management. She analyzes changes in steel industry from restructuring in the 1990s until now. In last time Assoc. Prof. B. Gajdzik describes and analyses changes in enterprises towards Industry 4.0. She is the author of more than 500 publications [ORCID: 0000-0002-04081691] including books about management. She is the expert for steel industry market in Poland. Her scientific books mainly are about changes in steel industry in Poland, including using statistic models in the research of the sector.

The article has been reviewed.

Received in January 2019; accepted in April 2021.

This article is an Open Access article distributed under the terms and conditions of the Creative Commons Attribution 4.0 (CC BY 4.0) License (http://creativecommons.org/licenses/by/4.0/). 